\title{
ORFEU DE CARAPINHA
}

Resenha do livro:

AZEVEDO, Elciene. Orfeu de Carapinha. A trajetória de Luiz Gama na imperial cidade de São Paulo. Campinas: Editora da UNICAMP, Centro de Pesquisa em História Social da Cultura, 1999.

Resenha de

Surya Aaronovich Pombo de Barros

$U F P B / U S P$

Perseguir a originalidade de Luiz Gama e evidenciar suas contradições são os principais objetivos do livro Orfeu de Carapinha, de Elciene Azevedo. Fruto da pesquisa desenvolvida no mestrado em História na UNICAMP e publicado em 1999, a obra é apresentada por Silvia H. Lara, orientadora do trabalho original e prefaciada por Sidney Chalhoub, recebendo a chancela desses reputados pesquisadores da escravidão e pós-abolição brasileiros. Chalhoub salienta a importância da pesquisa e alerta para o risco trazido por um personagem dessa estirpe: o perigo de "sucumbir ao poder do mito, à força da legenda" ( $p$. 16). A autora se esforça nesse sentido, chamando reiteradamente a atenção dos leitores para a necessidade de entender Gama dentro de seu contexto.

Além da Introdução e Conclusão, a obra está dividida em quatro capítulos: 1 - Ao som da marimba, quando a autora discute a publicação do livro de poesias de Luiz Gama em 1859 e sua entrada na vida pública; 2 - Em meios brancos, centrado nos anos entre 1869 e 1871, período de conquista de espaço na imprensa paulistana; 3 - Um sonho de República, no qual Azevedo debate a presença de Gama no Partido Republicano Paulista; e 4 - O rábula da liberdade, que se debruça sobre sua atuação nos tribunais judiciários em defesa da liberdade de escravos entre 1868 e 1882.

Utilizando como imprensa e textos de Raul Pompéia e Sud Menucci, no capítulo introdutório a autora apresenta Luiz Gama a partir da repercussão de sua morte em 1882, defendendo que ele "projetara-se como 'homem de letras' através de sua poesia, do jornal e da militância política" (p. 23). Ela não aprofunda essa questão, não dialoga com a história dos intelectuais e não se refere a Luiz Gama como intelectual nem discute essa possibilidade, embora a tônica do livro seja o tratamento como personagem de destaque na cena política e intelectual paulista (e brasileira), que se movimentou no mundo dos brancos sendo autointitulado negro. Azevedo critica a ideia de homem à frente de seu tempo ou sobrehumano, como algumas obras o trataram. Ela discute algumas interpretações existentes: o abolicionista radical, resultado da origem baiana e da mãe africana livre envolvida nas insurreições da década de 1830, construída por Sud Menucci; a de J. Romão da Silva que o analisou como literato, mas a partir da vida do poeta, tão extraordinária que para ele seria "impossível fazer arte pela arte" (p. 25); e finalmente a de Luiz Silva, que o trata como precursor da consciência negra. Ainda que reconheça a importância desses trabalhos, simultaneamente suas fontes e referências, Azevedo critica a construção de um "perfil mais ou menos consensual de Luiz Gama em detrimento das dimensões ambíguas e muitas vezes contraditórias de sua atuação" (p. 29). A partir dessa premissa, anuncia o desejo de perseguir a complexidade e a ambiguidade do personagem, justificando que a experiência de Gama pode explicitar estratégias que "este negro lançou mão para, dentro de um mundo branco e senhorial, ter uma eficaz atuação em favor da liberdade de outros escravos" (p. 30).

O primeiro capítulo, centrado no livro Primeiras trovas burlescas de Getulino, de 1859, tem como principais fontes as correspondências de Luiz Gama e sua autobiografia, publicada por Sud Menucci em 1938. Preliminarmente a autora retoma o início da vida de Gama: o nascimento como livre em Salvador, em 1830, filho de fidalgo português e africana 
livre, que aos dez anos de idade é vendido como escravo pelo pai para pagar dívidas de jogo, desembarcando no Rio de Janeiro, onde é comprado pelo alferes Antonio Pereira Cardoso, comerciante de escravos que o leva a São Paulo e, por não conseguir vendê-lo, o mantém a seus serviços para lavar, passar, engomar e costurar. Aprende a profissão de sapateiro e aos 17 anos aprende a ler com um hóspede da casa, estudante de Direito. Após obter a liberdade - não explicada na autobiografia -, ingressa na Força Pública e paralelamente exercita os conhecimentos das letras como copista e amanuense. A publicação da única obra literária representaria a inserção definitiva de Gama no mundo das letras e a primeira oportunidade de expressar publicamente "sentimentos e ideais", momento em que ele "começou a dar os primeiros tons de suas lutas, propostas e projetos políticos" (p. 40) através da sátira, um meio de expressão comum à época. A autora analisa alguns versos, demonstrando o "satirizar e criticar" os costumes, a política e os poderosos. Ele já se apresenta como negro ou bode, demarcando o pertencimento racial, característica que se repete em sua trajetória. Afirmando analisar os poemas para além das questões políticas ou estéticas, Azevedo reitera procurar neles o autor, entender o posicionamento do ex-escravo num mundo que não é seu - mundo branco e letrado - ideia que ela persegue no livro. Ao destacar os elementos presentes nos poemas - negro, ex-escravo, origem africana, dá um sentido curiosamente atual às falas/poesias dele, vendo ali a valorização da ascendência africana, destacando sua africanidade: "a identidade que Luiz Gama se esforça em construir em seus poemas ultrapassa as fronteiras étnicas, e se constitui sob uma única identidade africana. Estas questões talvez fiquem mais claras se pensarmos de onde vem essa 'africanidade' e por que se constitui tão fortemente nos escritos de um crioulo que, de uma forma ou de outra, circulava em um mundo letrado e branco, sendo relativamente bem aceito" (p. 67). Gama seria a síntese entre filho de africana e se mover no mundo branco.

O capítulo "Em meios brancos" debate a inserção de Gama em três espaços: maçonaria, política e imprensa. Os três âmbitos seriam interligados por sua motivação: abolicionismo e republicanismo. A autora discute a criação do Club Radical Paulista, em 1868, e a atuação de Luiz Gama nesse espaço, composto por um grupo que mais tarde estaria nas fileiras do Partido Republicano Paulista - os "radicais": polêmicas na imprensa, disputas internas, publicação de jornais para divulgar programas. E continua acompanhando sua trajetória nesse meio: em 1868 era "aprendiz da arte tipográfica" no jornal O Ipiranga, nas horas vagas da secretaria de polícia. No ano seguinte, aparece como redator de $O$ Radical Paulistano. Ela debate a posição do grupo e sua concepção de liberdade, a relação entre monarquia e escravidão, defendendo que Gama convivia e partilhava de certos ideais de homens brancos de destaque na sociedade, não apenas no Club Radical como na maçonaria. Ela discute a Loja América e a missão de, iluminados, levar "luzes à população" através da caridade e da filantropia, meios para buscar 'regeneração social', o que conduziria ao progresso, projeto político do grupo que compunha a Loja - espaço de sociabilidade da "elite ilustrada". A atuação de Gama - participação na escola noturna de primeiras letras, na Biblioteca Popular e especialmente na "comissão especial" para libertação de escravos e manutenção de libertos - segundo a autora, foi definida por suas "experiências de vida completamente distanciadas" dos demais, o que ajudaria a explicar esta "a princípio incomum parceria entre um ex-escravo e outros membros da Loja América”. (p. 95). Ela discute a invisibilidade da família em sua vida pública, e as poucas menções existentes em suas cartas pessoais sobre a esposa e o filho. Nestas, aparece a penúria em que viviam e uma questão cotidiana: "a dos laços de dependência que lhes garantia uma vida mais confortável" (p. 99). Azevedo considera que ele tinha "plena consciência do seu papel de dependente nas relações que lhe garantiam o destaque e o prestígio. O mesmo movimento que marcava a exclusão social experimentada por sua família [...] permitia a Gama figurar, com grande destaque, em clubes fechados como a maçonaria" (p. 99). E também agir, já que a sociedade maçônica de que participava seria pioneira na empreitada a favor dos escravos. Ao mesmo 
tempo, muitos maçons eram proprietários de escravos, portanto não havia consenso sobre o fim da escravidão. Isso demonstraria a tensão para Gama frequentar aqueles espaços. A autora destaca também os conflitos com o poder, quando ele é demitido do cargo de amanuense por confrontar um juiz municipal na causa de um africano que defendia a liberdade. Ela discute o impacto da exoneração, já que diversos jornais publicaram artigos de sua autoria e também de seus defensores e detratores, se transformando numa polêmica em torno da liberdade e contra a monarquia, mas também entre Gama e o Conselheiro Furtado de Mendonça: "esta tensa 'negociação' entre protegido e protetor ajuda também a explicar a lógica que o fez, nestes anos, lutar ao lado de homens com vidas tão diferentes da sua" (p. 126). Ao mostrar os processos sofridos por calúnia e injúria, as ameaças de morte sofridas (assim como acontecia com outros advogados de escravos) e a insatisfação dos proprietários de escravos com suas ações, a autora afirma que ele apelava para relações de apadrinhamento para ameaçar quem o ameaçava. Ao mesmo tempo, tinha o apoio da plebe: seria admirado pelos excluídos e se apegava a isso para se proteger. A autora insere o personagem no clima de inquietação de senhores em relação aos escravizados, a partir de textos de proprietários acusando-o, por exemplo, de comunista, de incentivador da insurreição de escravos. Mas Azevedo demonstra que ele se definia como legalista e conservador, se opondo às perturbações da ordem porque isso não seria benéfico para o país ou para o Partido Republicano. Ao mesmo tempo em que condenava a ilegalidade, ela afirma que para ele "se as leis não vingassem e fossem corrompidas, a insurreição deixaria então de ser um crime para se tornar uma justa defesa de direitos desrespeitados" (p. 135). Os boatos sobre a radicalidade de Gama e a associação desse posicionamento com a Loja América e, consequentemente, com a maçonaria e o Partido Republicano, para ela, demonstram sua delicada posição: de um lado, aceitação às regras e condutas do mundo branco, de outro introduzia radicalidade a esse mundo. É com o objetivo de discutir a especificidade, ou originalidade de Gama que se desenvolve o terceiro capítulo, "Um sonho de República". Azevedo insiste na tônica da atuação de Luiz Gama entre dois polos: sua busca por um tipo de sociedade (via republicanismo e fim da escravidão) e as possibilidades que o mundo dos brancos permitia. Negando a historiografia que considera que Gama rompeu com o Partido Republicano e o conservadorismo dos fazendeiros paulistas que faziam parte dele, em função de seu posicionamento sobre a abolição, ou seja, "em busca de uma imagem coerente do abolicionista negro" (p. 145), a autora mostra que não houve uma ruptura total, que ele continuava a participar de congressos e reuniões do Partido. Para a autora, Gama seguia uma lógica própria. Mas, como em outros momentos, essas divergências não eram individuais, Gama não estava sozinho. Ela menciona uma "facção Luiz Gama" (p. 157), mostrando o grupo do qual ele participava, mas defende que seu nível de radicalidade era maior no tocante às questões da escravidão - vista como urgente, da aliança (ou não) com partidos que apoiavam a monarquia do que o de seus apoiadores. Através da imprensa, a autora mostra o reconhecimento pelos pares e seu prestígio, mas também como era alvo de críticas nas polêmicas políticas. Para ela, "a opção partidária feita por Luiz Gama ainda em meados de 1870 e levada a cabo durante toda a sua vida, negada pela maioria dos estudos sobre ele, revela-se assim muito coerente com a sua propaganda abolicionista. De forma muito clara a luta pela República significava, para ele, a busca da liberdade e da igualdade - muito mais do que da fraternidade, ameaçada por estes tempos pela radicalidade que ele ia assumindo em suas posições" (p. 188).

$\mathrm{Na}$ atuação como defensor de escravos em processos judiciais que a autora vê a mais importante contribuição de Luis Gama. Esse é o foco do último capítulo do livro, "O rábula da liberdade". Ela apresenta brevemente a aproximação de Gama como o mundo jurídico: não frequentou a Academia, mas "desde algum tempo já empenhava-se em entender e dominar os meandros da lei” (p. 190), fosse como funcionário da Secretaria de Polícia, protegido do delegado Conselheiro Furtado de Mendonça, leitor da biblioteca da Faculdade 
de Direito de São Paulo ou como membro do corpo de jurados do Tribunal do Júri. Insistindo na tese da diferença entre Luiz Gama e contemporâneos, ela o compara a bacharéis que também atuavam em processos de escravos, apontando para a radicalidade de sua ação, que o teria levado ao reconhecimento público. Analisando alguns processos judiciais, Azevedo afirma que a defesa dos "direitos dos desvalidos" (p. 206) era a principal marca de sua atuação nesse mundo: "Luiz Gama conseguia manejar com habilidade todo um conjunto de códigos e significados que envolviam este ambiente de magistrados e acadêmicos - brancos para tornar viável sua luta" (p. 206). Ela narra casos jurídicos, apresentando as "armas de Luiz Gama neste período" (p. 227): leitura particular da legislação, astúcia na utilização da imprensa para dar publicidade a suas ideias e jogar com a opinião pública a seu favor, pressionando juízes e advogados contrários. Com sarcasmo, irreverência, ousadia e subversão da hierarquia: "o advogado negro, mesmo dentro dos códigos estabelecidos e compartilhados da própria jurisprudência, conseguia muitas vitórias na sua batalha abolicionista" (p. 245). A autora finaliza defendendo que Gama foi aglutinador de um movimento jurídico pela libertação de escravos, sendo epicentro de uma rede de apoio, "transformando-se, portanto, em uma figura de destaque no que dizia respeito às questões de liberdade na capital, ele passara a simbolizar praticamente sozinho a luta em favor da abolição" (p. 260). Segundo ela, ele era "ponto de ligação entre dois mundos que pouco se tocavam fora das relações de domínio - o dos fidalgos rapazes das academias superiores e o dos escravos que buscavam se libertar -, Luiz Gama tinha então garantido seu prestígio e provado a eficácia de sua ação" (p. 264).

O breve capítulo "Conclusão" narra a repercussão da morte de Gama, e encerra o livro, iniciado com o mesmo episódio. A comoção pela interrupção da vida do advogado no auge de luta abolicionista é vista pela autora como justificada após o exame de sua atuação: "o desenrolar da história do filho de Luiza Mahin descortina experiências forjadas no calor de tantas solidariedades e de tantos conflitos que a cena do enterra, tal qual foi descrita pelos inúmeros jornais da época, já não é incompreensível para um leitor da posteridade” (p. 266). Ela retoma alguns aspectos de sua análise, especialmente a ideia de síntese entre africanidade baiana e circulação em meios brancos e senhoriais em São Paulo, representada pela presença de imigrantes operários, libertos e escravos e homens brancos de elite no enterro. Apesar da preocupação anunciada, de não sucumbir ao tamanho do personagem, encerra com a reafirmação de sua singularidade: "Durante sua vida, ele próprio construiu uma legenda em diferentes momentos, muitas vezes marcados pelo conflito e nem sempre intencionalmente. Essa foi a estratégia e arma importantes para que pudesse mudar o destino de muitos escravos. Através dela procurava ser reconhecido perante a sociedade paulista como o 'Orfeu de carapinha', um homem letrado, advogado, integrado ao mundo dos cidadãos brancos, mas que não deixava ninguém esquecer que havia sido escravo, e fazia absoluta questão de afirmar-se negro" (p. 270).

Embora Orfeu de Carapinha não se vincule a teorias sobre intelectuais na perspectiva política, sociológica ou da história, nem se remeta à história da educação, a obra possibilita a reflexão sobre Luiz Gama como intelectual negro. É importante destacar a ideia da originalidade de Gama, tão perseguida pelos autores que o analisaram antes e reafirmada por Azevedo. É importante perceber que Gama não atuou solitariamente, não gênio foi o criador, individualidade única e insubstituível ${ }^{1}$. Pelo contrário, como demonstrado (mas pouco destacado pela autora), Gama foi o resultado de sua origem - negra e africana amalgamada ao mundo branco -, mas também de suas experiências ao longo da vida. Podemos perceber na trajetória de Gama seu contato com o mundo letrado em diversos momentos - através do estudante que possibilitou sua inserção nas letras, assim como suas colocações posteriores que mantinham esse contato ${ }^{2}$. Embora a autora insista na separação entre Gama e o mundo dos brancos, poderíamos questionar essa polarização: o fato dele ser publicado em jornais de diferentes posições políticas, por exemplo, é pouco discutido pela 
autora. Usando esses textos como fontes, ela não levanta possíveis motivações para os editores aceitarem publicar textos muitas vezes polêmicos e provocativos para monarquistas e diferentes tipos de republicanos, assim como para senhores de escravos e seus apoiadores (juízes, advogados).

Azevedo trata Gama como personagem singular, mas durante todo o livro vemos que sua atuação não é isolada: nas polêmicas partidárias seus artigos são assinados com correligionários ou subscritos por outros; na atuação como advogado de escravos, por vezes divide o escritório de advocacia ou as causas judiciais, ele não age sozinho, pertence a uma geração, cultiva uma sociabilidade que reflete o período e seus pares ${ }^{3}$ - via imprensa, participação em reuniões maçônicas ou partidárias. Nos atestados médicos para as ações de escravos (desvalorizando seu preço), por exemplo, ele contava com a assinatura de médicos com quem mantinha relações de amizade e de aliança em relação à causa abolicionista. Mesmo sua formação, atípica quando comparada a outros personagens (brancos) - ou seja, aprendizado tardio da leitura, formação longe da academia de direito -, pode ser comparada a de outros homens negros incomuns que compartilhavam a experiência de ser ex-escravo ou descendente de escravos.

No capítulo mais interessante do livro, onde a autora deixa transparecer a admiração por seu objeto de pesquisa, ao tratar da atuação de Gama na defesa dos escravizados, entre outros advogados com quem trabalhou ela menciona José Rubino de Oliveira, que endossava sua interpretação em determinadas ações judiciais. Mas ela não alude à origem de Rubino de Oliveira, também negro ${ }^{4}$. Apesar das diferenças em suas trajetórias, essa característica poderia trazer possibilidades interessantes de análise: essa origem racial comum traria algum impacto para sua convivência e posicionamento?

A movimentação de Luiz Gama no espaço público, utilizando a imprensa a favor de suas causas, se apoiando na opinião pública contra os desafetos e o impacto dessa estratégia, assim como sua relação com o poder ${ }^{5}$ instituído - seja contando com a proteção de poderosos, seja se posicionando politicamente, são aspectos que também remetem à categoria intelectual, mas Azevedo não a utiliza ou seus teóricos na análise. Vale notar que apesar da relação com o campo político, ao contrário do que se verifica sobre o campo intelectual brasileiro, em que intelectuais estão costumeiramente associados ao poder de maneira dependente, Gama foi funcionário público por poucos anos, perdendo o emprego num episódio polêmico e por conta de um posicionamento determinado e pena mordaz. Posteriormente, sua sobrevivência não contou diretamente com o qualquer cargo ou público.

Apesar dessas observações, a obra de Elciene Azevedo convence o leitor sobre a singularidade de Luiz Gama. Destemido, mordaz, astuto, o ex-escravo que dedicou parte da vida pública a lutar em favor de escravizados atuando como advogado e falando "de igual para igual" com homens brancos, políticos, proprietários, poderosos, assim como com o povo pobre e pessoas de cor se destaca na história brasileira, e o livro de Azevedo atinge seus objetivos ao analisá-lo. Outros trabalhos podem continuar a tarefa, quiçá utilizando o instrumental oferecido pela história dos intelectuais.

\footnotetext{
${ }^{1}$ BOURDIEU, Pierre. Campo do poder, campo intelectual e habitus de classe. In: A economia das trocas simbólicas, São Paulo: Perspectiva, 1999.

${ }^{2}$ HÉBRARD, Jean. O autodidatismo exemplar. Como Valentin Jamerey-Duval aprendeu a ler? In: CHARTIER, Roger (Org.). Práticas da leitura. São Paulo: Estação Liberdade, 1996.

${ }^{3}$ SIRINELLI, Jean François. Os intelectuais. In: RÉMOND, René (Org.). Por uma história política. $2^{\mathrm{a}}$ ed. Rio de Janeiro: FGV, 2003.

${ }^{4}$ PORTES, Écio A.; CRUZ, Ricardo A. da. Trajetórias e estratégias sociais e escolares do pardo José Rubino de Oliveira (1837-1891): da selaria em Sorocaba às arcadas jurídicas do Largo de São Francisco, São Paulo. In: PEREIRA, Lúcia H. P.; OLIVEIRA, Wanderley C. (Org.). Práticas educativas: discursos e produção de saberes. Rio de Janeiro: E-papers, 2007, paginação irregular.

${ }^{5}$ BOBBIO, Norberto. Intelectuais. In: Os intelectuais e o poder. São Paulo: UNESP, 1997.
} 